Karly Regan ${ }^{1}$, David Ordosch, Karl. D. Glover, Kelley J. Tilmon², and Adrianna

Szczepaniec $3^{*}$

\title{
Effects of a pyrethroid and two neonicotinoid insecticides on population dynamics of key pests of soybean and abundance of their natural enemies
}

Department of Plant Science, South Dakota State University, Brookings, SD, 57007, USA

${ }^{1}$ Present address: Department of Entomology, Pennsylvania State University, 501 ASI Building, University Park, PA, 16802

${ }^{2}$ Present address: Department of Entomology, Ohio State University, Wooster, OH 44691, USA

${ }^{3}$ Present address: Department of Entomology, Texas A\&M AgriLife Research, Amarillo, TX 79106, USA

*Corresponding author: Department of Entomology, Texas A\&M AgriLife Research, 6500 Amarillo Blvd. W, Amarillo, TX 79106, USA. Email:

Ada.Szczepaniec@ag.tamu.edu; telephone: 806-354-5806; fax: 806-677-5644 


\section{Abstract}

Neonicotinoids alone and in combination with pyrethroid insecticides are common in crop production and effectively suppress target herbivores. The goal of this research was to quantify the effects of these insecticides on primary and secondary pests of soybeans and their natural enemies. We examined the effects of neonicotinoids alone applied to soybean seeds (thiamethoxam), neonicotinoids and pyrethroids applied to leaves (imidacloprid $+\beta$-cyfluthrin), and a combination of these treatments on arthropod abundance in soybean fields at two locations over two years in eastern South Dakota. Foliar applications of the insecticides suppressed soybean aphids, Aphis glycines Matsumara (Hemiptera: Aphididae), while thrips, (Thysanoptera: Thripidae) increased in numbers following exposure to the neonicotinoid insecticides alone or in combination with the pyrethroid in one of the locations and were significantly correlated with their major predators. Spider mites (Tetranychus urticae Koch) were not significantly affected by treatments. We also noted suppression of several taxa of predators following exposure to the insecticides. While low arthropods abundance in the first year of the study limits our inferences, we conclude that both insecticide classes effectively suppress the key pest of soybean, soybean aphids, while their impact on secondary pests and on predators is variable. This research provides important contribution to our understanding of target and non-target impacts of insecticides commonly used in crop protection. 
Keywords: thiamethoxam, imidacloprid, $\beta$-cyfluthrin, Aphis glycine, Tetranychus urticae, Sericothrips variabilis, Frankliniella occidentalis, seed treatments, non-target effects 


\section{Introduction}

Soybeans are the second most widely planted field crop in the United States and 30 million hectares of soybeans were planted in 2012, accounting for $23 \%$ of the total hectares of field crops cultivated in the United States (National Agricultural Statistics Service, 2013). Until 2005, soybean was scouted for insects and treated with insecticides only sporadically (Ragsdale et al., 2011) owing to infrequent and sparse pest outbreaks. However, following the invasion of the soybean aphids (Aphis glycines (Hemiptera: Aphididae), which quickly became the key pest of the crop (Ragsdale et al., 2011), insecticide use in soybean increased rapidly. Particularly, applications of neonicotinoid insecticides, thiamethoxam and imidacloprid, and a pyrethroid insecticide cyfluthin rose significantly since 2005. Combined volume of both neonicotinoids, for example, averaged 0.56 million kilograms annually between 2010 and 2014, while volume of cyfluthrin exceeded 0.022 million kilograms in the same timespan (USGS 2016). All of these insecticides were applied at a fraction of these volumes between 2005 and 2009, and were virtually absent in soybean prior to 2005 (USGS 2016).

Pyrethroids and neonicotinoids are frequently applied to soybeans to manage the aphids and provide adequate aphid control (Ohnesorg et al., 2009). Moreover, neonicotinoid insecticides are often applied as a seed coating to control the soybean aphids and bean leaf beetle, Cerotoma trifurcata Forster (Coleoptera: Chrysomelidae), vector of bean pod mottle virus (Magalhaes et al., 2009). Neonicotinoid insecticides can effectively reduce abundance of the soybean aphid and their efficacy has been reported previously (McCornack and Ragsdale, 2006; 
Ohnesorg et al., 2009). Soybeans grown from seeds treated with these insecticides, however, have a short window of effectiveness after planting and do not provide long-term suppression of the aphids (Magalhaes et al., 2009; Seagraves and Lundgren, 2012). This was illustrated in greenhouse experiments that reported toxicity of neonicotinoid seed treatments to the aphids in short-term studies, and field studies that indicated inconsistent suppression of A. glycine over the growing season using neonicotinoid seed treatments alone (Magalhaes et al., 2009; McCarville and O'Neal, 2013; McCornack and Ragsdale, 2006; Ohnesorg et al., 2009; Seagraves and Lundgren, 2012). Pyrethroids in general and cyfluthrin in particular can effectively suppress key pests of soybean (Ohnesorg et al., 2009), although secondary outbreaks of non-target pests frequently follow pyrethroid applications owing to elimination of insect predators (Penman and Chapman, 1988; Raupp et al., 2010).

While neonicotinoids and pyrethroids effectively suppress target pests, their non-target effects can have significant implications for plant protection and management of insects and mites attacking crops (Desneux et al., 2007). For example, neonicotinoids have been shown to elevate populations of unsusceptible herbivores spider mites (Acari: Tetranychidae). Specifically, eruptive population increases of spider mites following applications of neonicotinoid insecticides were demonstrated in several agricultural plants including hops (Humulus lupulus L.) (James and Vogele, 2001), cotton (Gossypium hirsutum L.) (Smith et al., 2013; Szczepaniec et al., 2013), corn (Zea mays L.), and tomato (Solanum lycopersicum L.) (Szczepaniec et al., 2013). Moreover, numerous greenhouse and laboratory studies 
report that neonicotinoid insecticides are toxic to insect (Douglas et al., 2015; Fogel et al., 2013; James, 2003a; Moser and Obrycki, 2009; Mullin et al., 2005; Rogers et al., 2007; Sclar et al., 1998; Seagraves and Lundgren, 2012; Smith and Krischik, 1999; Stavrinides and Mills, 2009; Szczepaniec et al., 2011) and mite (Bostanian et al., 2009; James, 2003b; Poletti et al., 2007; Stavrinides and Mills, 2009) predators. Pyrethroid insecticides have similar non-target impacts on insect predators and secondary pests. For example, pyrethroids are frequently linked to significant decreases in populations of insect predators through direct toxicity and their applications can cause outbreaks of non-target pests (Penman and Chapman, 1988; Raupp et al., 2010). These unintended consequences of pyrethroids have been implicated in cases of outbreaks of spider mites and thrips (Cordeiro et al., 2013; Gerson and Cohen, 1989; Hardin et al., 1995). It is noteworthy that the majority of literature reporting negative effects of these insecticides on predators is based on greenhouse or laboratory studies. Field research, on the other hand, is more likely to reveal variable consequences of insecticide exposure to natural enemies, such as effective suppression of green peach aphids (Myzus persicae Sulzer, Hemiptera: Aphididae) by its parasitoid following applications of a pyrethroid insecticide (Desneux et al., 2005) or lack of consistent reduction in abundance of predators following imidacloprid drenches in elm trees (Szczepaniec et al., 2011). Thus, the goal of this research was to quantify the impact of commonly used pyrethroid and neonicotinoid insecticides on target and non-target organisms associated with soybean. In field experiments carried out at two locations in eastern South Dakota over two years, we investigated the effects of thiamethoxam seed 
treatments, imidacloprid $+\beta$-cyfluthrin foliar sprays, and combination of the two formulations of these neonicotinoid insecticides on abundance of herbivores (soybean aphid, spider mites, and thrips) and their predators (lady beetles, predatory bugs, predatory flies, and lacewings among others) in soybeans. Our selection of insecticides (two neonicotinoids and a pyrethroid) and their formulations (seed treatments and foliar) was driven by common practices of soybean producers in the region.

\section{Materials and methods}

2.1 Field locations, planting, and harvest

The field experiments took place at two South Dakota State University Research Farms: Volga (Brookings County, South Dakota) and South Shore (Codington County, South Dakota). Glycine max L. (var. S15-L5 and S14-J7 in 2013 and in 2014, respectively, Syngenta Crop Protection, LLC, Greensboro, NC, USA) was planted on 5 June 2013 and 30 May 2014 at Volga, and on 13 June 2013 and 5 June 2014 at South Shore. The experiments were arranged in a randomized complete block design with plots measuring $3 \mathrm{~m}$ by $12 \mathrm{~m}$ separated by $3 \mathrm{~m}$ buffers in both years. Plots were planted to approximately 445,000 seeds per hectare with $0.76 \mathrm{~m}$ row spacing. Buffers were planted with soybean (var. 06942 in 2013, Mustang Seeds, Madison, SD, USA; var. S15-L5 in 2014, Syngenta Crop Protection). Glyphosate (Roundup WeatherMAX®, Monsanto Company, St. Louis, MO, USA) was applied to plots at the recommended rate of $2.34 \mathrm{~L}$ per hectare at both locations as needed each year to suppress weeds. Plots were harvested on 28 October 2013 and 
6 October 2014 at Volga and on 14 October 2013 and 14 October 2014 at South Shore. All plots were harvested using a two-row combine and measurements of weight and moisture of seed were taken. Yield was calculated using a formula to correct for $13 \%$ moisture (yield=[100-actual moisture ${ }^{*}$ test weight*100.138/ plot length/row spacing/number of rows).

\subsection{Pesticide treatments}

At Volga in 2013, we tested the effects of the following three treatments on the abundance of spider mites, their predators, and other relevant arthropods: untreated seed that received a fungicide seed treatment only ("Untreated"; ApronMaxx $^{\circledR}, 2.5 \mathrm{~g}$ fludioxonil per $100 \mathrm{~kg}$ of seed, $7.5 \mathrm{~g}$ mefenoxam per $100 \mathrm{~kg}$ of seed, Syngenta); untreated seed with foliar application of imidacloprid and $\beta$ cyfluthrin ("Foliar"; fungicide seed treatment + Leverage $360^{\circledR}, 239.68 \mathrm{~g}$ imidacloprid per L, 119.84 g $\beta$-cyfluthrin per L, Bayer CropScience LP, Research Triangle Park, NC, USA); and thiamethoxam-treated seed ("Seed"; fungicide seed treatment + CruiserMaxx ${ }^{\circledR}, 50 \mathrm{~g}$ thiamethoxam per $100 \mathrm{~kg}$ seed, $2.5 \mathrm{~g}$ fludioxonil per $100 \mathrm{~kg}$ of seed, 7.5g mefenoxam per $100 \mathrm{~kg}$ of seed, Syngenta). In 2014 at Volga and in both years at South Shore, an additional treatment of thiamethoxam-treated seed combined with foliar imidacloprid $+\beta$-cyfluthrin spray was added ("Seed + Foliar"; fungicide seed treatment + CruiserMaxx $^{\circledR}$, Leverage $360^{\circledR}$, Bayer). Soybean seed is routinely treated with fungicides in eastern South Dakota owing to high incidence of fungal diseases and we omitted the 'naked seed' treatment (i.e., no fungicide) due to high probability of disease development. Moreover, Leverage 
$360 ®$, a foliar insecticide with two active ingredients (a neonicotinoid and a pyrethroid) was selected based on prevalent farmer practices in the area. Plots assigned to the "Seed" treatment did not receive any foliar insecticide applications. The foliar insecticide was applied at the label rate of $204.52 \mathrm{~mL}$ per hectare on 16 August 2013 at Volga and on 23 August 2013 at South Shore using a $\mathrm{CO}_{2}$ backpack sprayer under 20 psi pressure, with a flat fan nozzle (TeeJet, XR110015) at $0.5 \mathrm{~m}$ (20 inch) spacing, delivered at $95 \mathrm{~L} / \mathrm{ha}$. In 2014, foliar applications of the insecticide were administered at the label rates on 11 August at Volga and 19 August at South Shore. All of the foliar applications of imidacloprid $+\beta$-cyfluthrin coincided with soybean aphids reaching the established action threshold of 250 aphids per plant (Ragsdale et al., 2007) at Volga location, which was surrounded by a wooded area containing buckthorn, the overwintering host of soybean aphids. Each treatment at the Volga location was replicated four times in both years. All four treatments were replicated six times at South Shore in both years.

\subsection{Arthropod sampling}

Arthropods were collected from plots using two methods: excised leaves and pheromone-free white sticky traps (Insect Trap and Monitor, EPA Est. \#48377-NY1, Model \#288-I). Leaves were were sampled from 2 August 2013 until 11 September 2013 and from 24 July 2014 until 12 September 2014. In 2013, the second youngest trifoliate (i.e., three leaves) was removed from seven randomly selected plants in each plot every 7 d. In 2014, three trifoliates (i.e., nine leaves) were selected from upper, mid, and lower portion of the canopies of four randomly 
selected plants in each plot every $10 \mathrm{~d}$. Leaves from each plant were bagged into a single ziplock bag and were transported back to the laboratory in coolers and refrigerated until samples were processed. All arthropods present on leaves except for spider mites were counted on each leaf using a dissecting microscope (Leica EZ4 HD, North Central Instruments, Plymouth, MN, USA). Arthropods encountered on leaves included soybean aphids, lacewings, and thrips. Leaves were then run through a mite brush (Model 2836M, BioQuip Products, Rancho Dominguez, CA, USA) in order to remove all spider mites and assess their density per leaf area measured using a portable leaf area meter (Model LI-3000C, LI-COR Biosciences, Lincoln, NE, USA). All leaves were processed within $10 \mathrm{~d}$ of collection.

Insects were passively sampled by pheromone-free sticky traps placed on 10 plants throughout each plot and collected after they had remained on the plants for one week. Traps' total adhesive area was $170 \mathrm{~cm}^{2}$, and each individual trap was cut into three pieces that were wrapped around soybeans plants, sticky side out, and distributed throughout the canopy of each plant. Arthropods associated with soybean plants were surveyed using the sticky traps every other week from midJuly until the end of August in each year and at each location. Relevant captured insects included Thripidae, Coccinnelidae, Anthocoridae, Chrysopidae, Syrphidae, and Dolichopodidae. Identifications were made using keys available within Triplehorn and Johnson (2005).

2.4. Statistical analysis 
The abundance of each arthropod taxon was summed for the season to compare relative abundance of the taxa with individual plots serving as replicates. Thrips were the only taxa encountered on leaves and traps in significant numbers and thus their seasonal abundance measured by both sampling methods was combined for analyses and expressed as average number per plant. The effects of treatments on seasonal means of all collected arthropod taxa and mean soybean yields were compared using an ANOVA in SAS 9.3 (SAS Institute 2011, Cary, NC, USA) and R (R Core Team 2012). Owing to significant interactions between treatments and locations, each location was analyzed separately for both years of the study. Means separation tests (Tukey's Honestly Significant Differences test) were performed where appropriate. Square root transformations were performed when necessary in order to meet assumptions of normal distribution and homogeneity of variances for all analyses. Data that could not meet assumptions of normal distribution and homogeneity of variances following transformations were analyzed using a non-parametric Kruskal-Wallis test (Zar, 1999). To further assess relationships among herbivores and predators while controlling for insecticide applications we calculated partial correlations with log-transformed predators as independent variables and log-transformed herbivores as dependent variables. Partial correlations were performed in R (R Core Team 2012) using ppcor package (pcorr.test with Pearson's coefficient).

\section{Results}

3.1. Effects of the insecticides on herbivores 
Insecticidal applications had significant effects on abundance of several taxa of arthropods associated with soybean in both years and at both locations. Three herbivore taxa were prevalent in soybean in our experiments including soybean aphids, thrips (Sericothrips variabilis Beach and Frankliniella occidentalis Pergande), and spider mites (Tetranychus urticae Koch).

Abundance of soybean aphids was significantly reduced by insecticide treatments in all years and locations (Fig. 1). Numbers of aphids were significantly lowered by the insecticide applications at Volga in both years (2013: $F_{2,9}=45.73 ; P<$ $\left.0.001 ; 2014: F_{3,12}=7.48 ; P=0.004\right)$, although neonicotinoid seed treatments alone reduced aphid numbers in 2013 but not in 2014 (Fig. 1A). The insecticides had a comparable suppressive effect on soybean aphids across the two study years at South Shore (2013: $\left.F_{3,20}=13.54 ; P<0.001 ; 2014: X^{2}=17.54 ; d f=3 ; P<0.001\right)$, with the exception of neonicotinoid seed treatments that suppressed the aphids in 2014 but not in 2013 Fig. 1B). It is noteworthy that at both locations seed treatments had a similarly variable impact on abundance of soybean aphids, while foliar or foliar combined with seed applications consistently reduced numbers of soybean aphids in both years and at both locations (Fig. 1). On the other hand, foliar applications and combination of foliar sprays and seed treatments consistently reduced numbers of soybean aphids compared to control plots in both years at both locations (Fig. 1). For all years and locations, there were no significant differences in aphid numbers between plots that received foliar sprays and plots exposed to a combination of seed treatments and foliar applications of the insecticides. 
Numbers of thrips differed significantly among treatments in both years at Volga, but were unaffected by treatments in either year at South Shore in 2014 (Fig. 2). Predatory thrips were rare across years and locations (16 out of 7012 thrips collected or $0.25 \%$ ), thus data reflect abundance of herbivorous thrips, all of which were denoted as "Thripidae." The most common thrips collected were soybean thrips (S. variabilis) and western flower thrips (F. occidentalis). Neonicotinoid applications had a significant effect on numbers of Thripidae at Volga in both years (2013: $F_{2,9}=12.62 ; P<0.001 ; 2014: F_{3,12}=7.81 ; P=0.01$; Fig. 2 A). When compared to untreated plots, thrips increased in abundance (2013) or were unaffected (2014) by neonicotinoid seed treatments at Volga, while exposure to foliar sprays or combination of foliar and seed treatments of the insecticides resulted in elevated numbers of thrips in both years (Fig. 2A). Numbers of thrips did not differ among treatments at South Shore in $2013\left(F_{3,20}=1.82 ; P=0.624\right)$ or $2014\left(F_{3,20}=2.19 ; P=\right.$ 0.415) (Fig. 2B)..

Notwithstanding the prevalence of spider mites in plots exposed to foliar applications of the neonicotinoid and pyrethroid insecticides across years and locations, exposure to the insecticides did not significantly affect abundance of spider mites in 2013 (Volga: $X^{2}=0.26 ; \mathrm{df}=2 ; P=0.878$; South Shore: $X^{2}=2.72 ; \mathrm{df}=$ 3; $P=0.436$ ) or in 2014 (Volga: $F_{3,12}=1.59 ; P=0.204$; South Shore: $F_{3,20}=1.41 ; P=$ 0.251) (Fig. 3).

3.2. Effects of the insecticides on predators 
Predators collected passively on the traps included predatory flies (Diptera: Syrphidae and Dolichopodidae), lacewings (Neuroptera: Chrysopidae), lady beetles (Coleoptera: Coccinellidae), and predatory bugs (Hemiptera: Anthocoridae). Individual predator taxa that were significantly affected by treatments in 2013 at Volga included lady beetles $\left(F_{2,9}=5.12 ; P=0.007\right)$, predatory bug Orius insidiosus Say (Hemiptera: Anthocoridae), $\left(F_{2,9}=3.12 ; P=0.02\right)$, which were reduced by foliar applications of the insecticides but were unaffected by seed treatments, and Dolichopodidae $\left(F_{2,9}=4.21 ; P=0.017\right)$, which were reduced by seed treatments and foliar insecticides (Table 1). In 2014, O. insidiosus was marginally affected by treatments $\left(F_{3,12}=2.09 ; P=0.061\right)$, and numbers of these predators were the lowest in plots exposed to foliar+seed treatments (Table 1$)$. Numbers of lady beetles $\left(F_{3,20}=\right.$ 3.24; $P=0.023)$ and predatory bugs $\left(F_{3,20}=4.91 ; P=0.003\right)$ were lower in plots that received foliar insecticide applications with and without seed treatments at South Shore in 2013, while abundance of lacewings $\left(F_{3,20}=2.19 ; P=0.054\right)$ was reduced only in plots that were sprayed with imidacloprid and $\beta$-cyfluthrin in 2014 (Table 2).

\subsection{Correlations among herbivores and predators}

When we controlled for effects of insecticide treatments on relationships among the herbivores and predators we found a number of significant correlations between thrips and most of the predators (Table 3). In particular, thrips were negatively correlated with Anthocoridae, Chrysopidae, and Dolichopodidae at both locations in 2013 and in Volga in 2014, and with Syrphidae at South Shore in 2013 
and Volga in 2014. There were no significant partial correlations between soybean aphids and their major predators or spider mites and their major predators.

\subsection{Effects of the insecticides on soybean yield}

With one exception, neonicotinoid applications did not affect yield of soybean (Fig. 4). We observed no effect of treatments on yield at Volga in 2013 ( $F_{2,9}$ $=0.5 ; P=0.622$; Fig. $4 \mathrm{~A}$ ), while yield of soybean was significantly altered by treatments in $2014\left(F_{3,12}=9.65 ; P=0.002\right)$, whereby the untreated plots had lower yield than the other three treatments (Fig. 4B). Yield of soybeans did not differ among treatments at South Shore in both years $\left(2013: F_{3,20}=0.22 ; P=0.878 ; 2014\right.$ : $F_{3,20}=0.55 ; P=0.657 ;$ Figs. $4 \mathrm{C}$ and $\left.4 \mathrm{D}\right)$. The average yield at Volga in 2013 was $1174.84 \mathrm{~kg} / \mathrm{ha}$ whereas yield at South Shore averaged $1387.77 \mathrm{~kg} / \mathrm{ha}$ in 2013 and $1503.02 \mathrm{~kg} /$ ha in 2014.

\section{Discussion}

Insecticides have become a staple in agricultural crop protection, particularly their seed treatment formulations (Douglas and Tooker, 2016). Given the ubiquity of chemical pest suppression, target and non-target effects of insecticides on pests, predators and unsusceptible herbivores, and many other potential impacts on the environment (Bonmatin et al., 2015; Desneux et al., 2007; Goulson, 2013), should be examined in field crops. We demonstrated that use of two neonicotinoids and a 
pyrethroid had significant implications for their intended and unintended targets in soybean.

The target insect of foliar neonicotinoid imidacloprid and pyrethroid insecticide applications in soybean, soybean aphid was by far the most abundant arthropod taxon. Neonicotinoids alone and in combination with $\beta$-cyfluthrin generally reduced aphid abundance. Specifically, foliar or combination of foliar and seed applications of the insecticides consistently suppressed numbers of soybean aphids while seed treatments alone had a variable impact on these insects and reduced aphid abundance in two of four cases. Moreover, we did not note an additive suppressive effect of seed treatments combined with foliar applications on aphid abundance. This was not unexpected as seed treatments have a short window of effectiveness after planting (Magalhaes et al., 2009; Seagraves and Lundgren, 2012). Toxicity of neonicotinoid seed treatments to aphids has been documented in greenhouse and laboratory settings, but a reduction in abundance has not been consistently reported in field experiments (Magalhaes et al., 2009; McCarville and O’Neal, 2013; McCornack and Ragsdale, 2006; Ohnesorg et al., 2009; Seagraves and Lundgren, 2012). Foliar applications of neonicotinoid and pyrethroid provided consistent suppression of soybean aphids in our field experiments, on the other hand, an effect that has been illustrated previously (Ohnesorg et al., 2009). Toxicity of the foliar insecticide was the likely cause of aphid suppression in our experiments. Thus, our research provides further support for high efficacy of foliar neonicotinoid and pyrethroid insecticides against the aphids and inconsistent suppression of soybean aphids by neonicotinoid seed treatments alone. 
It is noteworthy that even when we accounted for the insecticide effects we did not find soybean aphids to be correlated with any of their major predators, most notably lady beetles. In fact, we noted relatively few lady beetles, especially at South Shore in both years. South Shore plots were surrounded by agricultural fields while Volga plots were relatively close to a shelter belt and a residential area, which may have affected lady beetle numbers by providing alternative prey, shelter, and nonprey food sources (Landis et al., 2000).

Neonicotinoid insecticides have been implicated in increases of spider mite populations, with a growing number of studies addressing this phenomenon in agricultural crops (Smith et al., 2013, Szczepaniec et al., 2013). Moreover, pyrethroid insecticides have been implicated in outbreaks of these herbivores since the 1980's (Gerson and Cohen, 1989; Hardin et al., 1995; Penman and Chapman, 1988 ), and $\beta$-cyfluthrin is often used to induce spider mite population growth in experiments (for example Van Steenwyk and Kiss 2010). Thus, we expected the insecticides to increase spider mite abundance in our experiments, particularly following exposure to the foliar sprays of neonicotinoid and pyrethroid insecticides. However, we observed only weak trends for higher prevalence and abundance of these herbivores in soybean. One of the factors that may have affected this outcome were relatively low numbers of spider mites in both years of the study across treatments, and especially in 2013. Neonicotinoid seed coating did not affect populations of spider mites in our study, which has been documented previously in a cotton system, where numbers of spider mites exhibited a weaker trend in population growth after exposure to seed treatments compared to foliar 
applications of a neonicotinoid insecticide (Szczepaniec et al. 2013). Continuing research on the impact of repeated use of the neonicotinoid seed treatments in crop production in combination with changing climatic conditions that may favor spider mite outbreaks is crucial in order to assess broader impact of neonicotinoids on these and other non-target organisms.

Neonicotinoids have low efficacy against phytophagous thrips, with thiamethoxam somewhat more toxic to thrips than imidacloprid when applied in comparable amounts (Broughton and Herron, 2009; Guillén and Bielza, 2013; Kay and Herron, 2010; Reisig et al., 2012). Moreover, pyrethroid insecticides have been speculated to increase thrips populations by enhancing their fitness, and a pyrethroid insecticide similar to one used in our study has been shown to increase thrips numbers previously (Frantz and Mellinger, 2009). Thus, we expected that thrips abundance would increase as a response to foliar insecticides and remain unaffected by seed treatments alone. This expectation was supported at one of the location but not the other. Further, we found that thrips were strongly correlated with predator numbers, particularly Anthocoridae, Chrysopidae, and Dolichopodidae across locations. While thrips were also negatively correlated with Syrphidae, this relationship was less consistent. $O$. insidiosus is an important predator of thrips (Butler and O'Neil, 2007), which it prefers over soybean aphids (Desneux and O'Neil, 2008), and predatory flies and lacewings prey on thrips as well (Sabelis and Van Rijn, 1997). We speculate that relaxation of predator pressure explains trends in thrips abundance that we observed. However, it is important to note that we did not start sampling the plants until August, and thus any early- 
season population dynamics of thrips in our plots that may have been affected be seed treatments were not captured,

Elimination of predatory arthropods has been one of the major foci of research on non-target consequences of pesticides (Lu et al., 2012), and we reported that insecticides used in our study lowered abundance of several key predators in soybean. Not surprisingly, we noted a consistent decrease in predator abundance following foliar insecticide applications whether they were combined with seed treatments or not. This was especially evident in abundance of predators of aphids such as lady beetles, predatory flies, and predatory bugs. Neonicotinoid and pyrethroid insecticides have been reported to harm predatory insects (Al-Deeb et al., 2001; Cloyd and Bethke, 2011; Moser and Obrycki, 2009; Stavrinides and Mills, 2009) including those associated with soybean and important in suppression of soybean aphids (Ohnesorg et al., 2009; Seagraves and Lundgren, 2012). Moreover, our research illustrated how elimination of predators can explain patterns of abundance of herbivores that are not affected by insecticide exposure. It is noteworthy that we did not document a negative impact of seed treatments alone on predatory insects in our study, an outcome that has been reported previously (Seagraves and Lundgren, 2012). We attribute this to a significant lapse of time between the peak concentrations of neonicotinoids in plants grown from treated seeds (up to $40 \mathrm{~d}$ following germination) and the onset of sampling. It is likely that the plants were no longer toxic and did not alter predator abundance in our experiments beyond the period of neonicotinoid toxicity in seed-treated plants. 
Improvement in crop yield is frequently the single most relevant factor driving applications of insecticides. Over the last five years the average use of imidacloprid and thiamethoxam alone increased over 16- and nearly 3-fold, respectively and a large proportion of this increase is driven by seed treatments (Douglass and Tooker, 2015). It is thus relevant to note that we did not observe any evidence that neonicotinoid insecticides applied to soybean seeds provided yield advantage in absence of the pests most likely to affect productivity of soybeans. Other studies report comparable lack of yield advantage when target pests do not exceed action thresholds (Magalhaes et al., 2009, Seagraves and Lundgren, 2012). This outcome further invalidates the prevalent practice of using seed treatments to boost crop productivity in absence of pest pressure or imminent insect infestations in first weeks after plant germination. On the other hand, foliar applications of the insecticides improved yield of soybeans when density of the key pest, soybean aphids reached moderate densities. Insecticide applications provide significant yield benefits when A. glycine populations exceed the established economic threshold, which has been demonstrated previously (Ragsdale et al,. 2007, McCarville and O'Neal, 2013) and supports the validity of using thresholds of pest densities as triggers for insecticide applications.

Field research is often plagued with limitations brought about by high yearto-year variability in arthropod numbers and challenges of drawing inferences from insufficient replication size that result in trends rather than significant differences among imposed treatments. Moreover, moderate temperatures and abundant rainfall frequently characterize growing seasons in the Northern Plains, which in 
general lower abundance of arthropods, as was the case in 2013. Our research was affected by these factors and thus our inferences are limited. While further research is necessary, this work contributes to our understanding of the risk associated with use of neonicotinoid insecticides in agroecosystems, particularly in the Northern Plains.

In conclusion, our data demonstrate consistent suppression of the key pest of soybean, A. glycine with foliar insecticides but provide little support for implementing seed treatments as a reliable tactic to control the aphid and improve productivity of soybean in eastern South Dakota. Given variability in pest pressure it is likely that threshold-based foliar insecticide applications would provide an effective, and more sustainable, management of soybean pests. We provide further evidence that foliar insecticides have detrimental impacts on predatory insects in soybean, which can have indirect consequences to herbivores not eliminated by insecticides. This work highlights the need to carry out long-term research at a larger scale and scope to assess the consequences of insecticides to target and nontarget organisms in crop plants.

\section{Acknowledgements}

The authors would like to thank D. Doyle, A. Heuer, B. McManus, and D. Vos for assistance with planting and harvesting, and A. DeNomme, R. Helget, A. Koch, P. Bartlett, S. Chi, and S. Maddenini for assistance with data collection. This research was supported by USDA AFRI grant (2012-67013-19346), National Institute for 
Food and Agriculture (H451-12), South Dakota Soybean Research and Promotion Council, and South Dakota State University Center for Excellence in Drought Tolerance Research.

\section{Conflict of Interest}

The authors declare no conflict of interest. 


\section{References}

Al-Deeb, M.A., Wilde, G.E., Zhu, K.Y., 2001. Effect of insecticides used in corn, sorghum, and alfalfa on the predator Orius insidiosus (Hemiptera: Anthocoridae). J. Econ. Entomol. 94, 1353-1360.

Bonmatin, J.-M., Giorio, C., Girolami, V., Goulson, D., Kreutzweiser, D.P., Krupke, C., Liess, M., Long, E., Marzaro, M., Mitchell, E.A.D., 2015. Environmental fate and exposure; neonicotinoids and fipronil. Environ. Sci. Pollut. Res. 22, 35-67.

Bostanian, N.J., Thistlewood, H.A., Hardman, J.M., Laurin, M.-C., Racette, G., 2009. Effect of seven new orchard pesticides on Galendromus occidentalis in laboratory studies. Pest Manag. Sci. 65, 635-639. doi:10.1002/ps.1721

Broughton, S., Herron, G.A., 2009. Potential new insecticides for the control of western flower thrips (Thysanoptera: Thripidae) on sweet pepper, tomato, and lettuce. J. Econ. Entomol. 102, 646-651.

Butler, C.D., O'Neil, R.J., 2007. Life history characteristics of Orius insidiosus (Say) fed diets of soybean aphid, Aphis glycines Matsumura and soybean thrips, Neohydatothrips variabilis (Beach). Biol. Control 40, 339-346.

Cloyd, R.A., Bethke, J.A., 2011. Impact of neonicotinoid insecticides on natural enemies in greenhouse and interiorscape environments. Pest Manag. Sci. 67, 3-9. doi:10.1002/ps.2015

Cordeiro, E.M.G., De Moura, I.L.T., Fadini, M.A.M., Guedes, R.N.C., 2013. Beyond selectivity: Are behavioral avoidance and hormesis likely causes of pyrethroid-induced outbreaks of the southern red mite Oligonychus ilicis? Chemosphere 93, 1111-1116.

Desneux, N., Decourtye, A., Delpuech, J.-M., 2007. The sublethal effects of pesticides on beneficial arthropods. Annu Rev Entomol 52, 81-106.

Desneux, N., Fauvergue, X., Dechaume-Moncharmont, F.-X., Kerhoas, L., Ballanger, Y., Kaiser, L., 2005. Diaeretiella rapae limits Myzus persicae populations after applications of deltamethrin in oilseed rape. J. Econ. Entomol. 98, 9-17.

Desneux, N., O’Neil, R.J., 2008. Potential of an alternative prey to disrupt predation of the generalist predator, Orius insidiosus, on the pest aphid, Aphis glycines, via short-term indirect interactions. Bull. Entomol. Res. 98, 631-639.

Douglas, M.R., Rohr, J.R., Tooker, J.F., 2015. EDITOR'S CHOICE: Neonicotinoid insecticide travels through a soil food chain, disrupting biological control of non - target pests and decreasing soya bean yield. J. Appl. Ecol. 52, 250-260.

Douglas, M.R., Tooker, J.F., 2016. Meta-analysis reveals that seed-applied neonicotinoids and pyrethroids have similar negative effects on abundance of arthropod natural enemies. PeerJ 4, e2776.

Fogel, M.N., Schneider, M.I., Desneux, N., González, B., Ronco, A.E., 2013. Impact of the neonicotinoid acetamiprid on immature stages of the predator Eriopis connexa (Coleoptera: Coccinellidae). Ecotoxicology 22, 1063-1071.

Frantz, G., Mellinger, H.C., 2009. Shifts in western flower thrips, Frankliniella occidentalis (Thysanoptera: Thripidae), population abundance and crop damage. Fla. Entomol. 92, 29-34. 
Gerson, U., Cohen, E., 1989. Resurgences of spider mites (Acari: Tetranychidae) induced by synthetic pyrethroids. Exp. Appl. Acarol. 6, 29-46.

Goulson, D., 2013. Review: An overview of the environmental risks posed by neonicotinoid insecticides. J. Appl. Ecol. 50, 977-987.

Guillén, J., Bielza, P., 2013. Thiamethoxam acts as a target - site synergist of spinosad in resistant strains of Frankliniella occidentalis. Pest Manag. Sci. 69, 188-194.

Hardin, M.R., Benrey, B., Coll, M., Lamp, W.O., Roderick, G.K., Barbosa, P., 1995. Arthropod pest resurgence: an overview of potential mechanisms. Crop Prot. 14, 3-18.

James, D.G., 2003a. Pesticide susceptibility of two coccinellids (Stethorus punctum picipes and Harmonia axyridis) important in biological control of mites and aphids in Washington hops. Biocontrol Sci. Technol. 13, 253-259.

James, D.G., 2003b. Toxicity of imidacloprid to Galendromus occidentalis, Neoseiulus fallacis and Amblyseius andersoni (Acari: Phytoseiidae) from hops in Washington State, USA. Exp. Appl. Acarol. 31, 275-281.

James, D.G., Vogele, B., 2001. The effect of imidacloprid on survival of some beneficial arthropods. Plant Prot. Q. 16, 58-62.

Kay, I.R., Herron, G.A., 2010. Evaluation of existing and new insecticides including spirotetramat and pyridalyl to control Frankliniella occidentalis (Pergande)(Thysanoptera: Thripidae) on peppers in Queensland. Austral Entomol. 49, 175-181.

Landis, D.A., Wratten, S.D., Gurr, G.M., 2000. Habitat management to conserve natural enemies of arthropod pests in agriculture. Annu. Rev. Entomol. 45, 175-201.

Lu, Y., Wu, K., Jiang, Y., Guo, Y., Desneux, N., 2012. Widespread adoption of Bt cotton and insecticide decrease promotes biocontrol services. Nature 487, 362-365.

Magalhaes, L.C., Hunt, T.E., Siegfried, B.D., 2009. Efficacy of neonicotinoid seed treatments to reduce soybean aphid populations under field and controlled conditions in Nebraska. J. Econ. Entomol. 102, 187-195.

McCarville, M.T., O'Neal, M.E., 2013. Soybean aphid (Aphididae: Hemiptera) population growth as affected by host plant resistance and an insecticidal seed treatment. J. Econ. Entomol. 106, 1302-1309.

McCornack, B.P., Ragsdale, D.W., 2006. Efficacy of thiamethoxam to suppress soybean aphid populations in Minnesota soybean. Crop Manag. 5.

Moser, S.E., Obrycki, J.J., 2009. Non-target effects of neonicotinoid seed treatments; mortality of coccinellid larvae related to zoophytophagy. Biol. Control 51, 487-492.

Mullin, C.A., Saunders, M.C., Leslie, T.W., Biddinger, D.J., Fleischer, S.J., 2005. Toxic and behavioral effects to Carabidae of seed treatments used on Cry3Bb1-and Cry1Ab/c-protected corn. Environ. Entomol. 34, 1626-1636.

Ohnesorg, W.J., Johnson, K.D., O'Neal, M.E., 2009. Impact of reduced-risk insecticides on soybean aphid and associated natural enemies. J. Econ. Entomol. 102, 1816-1826. 
Penman, D.R., Chapman, R.B., 1988. Pesticide-induced mite outbreaks: pyrethroids and spider mites. Exp. Appl. Acarol. 4, 265-276.

Poletti, M., Maia, A.H.N., Omoto, C., 2007. Toxicity of neonicotinoid insecticides to Neoseiulus californicus and Phytoseiulus macropilis (Acari: Phytoseiidae) and their impact on functional response to Tetranychus urticae (Acari: Tetranychidae). Biol. Control 40, 30-36.

Ragsdale, D.W., Landis, D.A., Brodeur, J., Heimpel, G.E., Desneux, N., 2011. Ecology and management of the soybean aphid in North America. Annu. Rev. Entomol. 56, 375-399.

Ragsdale, D.W., McCornack, B.P., Venette, R.C., Potter, B.D., MacRae, I.V., Hodgson, E.W., O’Neal, M.E., Johnson, K.D., O’neil, R.J., DiFonzo, C.D., 2007. Economic threshold for soybean aphid (Hemiptera: Aphididae). J. Econ. Entomol. 100, 1258-1267.

Raupp, M.J., Shrewsbury, P.M., Herms, D.A., 2010. Ecology of herbivorous arthropods in urban landscapes. Annu. Rev. Entomol. 55, 19-38.

Reisig, D.D., Herbert, D.A., Malone, S., 2012. Impact of neonicotinoid seed treatments on thrips (Thysanoptera: Thripidae) and soybean yield in Virginia and North Carolina. J. Econ. Entomol. 105, 884-889.

Rogers, M.A., Krischik, V.A., Martin, L.A., 2007. Effect of soil application of imidacloprid on survival of adult green lacewing, Chrysoperla carnea (Neuroptera: Chrysopidae), used for biological control in greenhouse. Biol. Control 42, 172-177.

Sabelis, M.W., Van Rijn, P.C., 1997. Predation by insects and mites.

Sclar, D.C., Gerace, D., Cranshaw, W.S., 1998. Observations of population increases and injury by spider mites (Acari: Tetranychidae) on ornamental plants treated with imidacloprid. J. Econ. Entomol. 91, 250-255.

Seagraves, M.P., Lundgren, J.G., 2012. Effects of neonicitinoid seed treatments on soybean aphid and its natural enemies. J. Pest Sci. 85, 125-132. doi:10.1007/s10340-011-0374-1

Smith, J.F., Catchot, A.L., Musser, F.R., Gore, J., 2013. Effects of aldicarb and neonicotinoid seed treatments on twospotted spider mite on cotton. J. Econ. Entomol. 106, 807-815.

Smith, S.F., Krischik, V.A., 1999. Effects of systemic imidacloprid on Coleomegilla maculata (Coleoptera: Coccinellidae). Environ. Entomol. 28, 1189-1195.

Stavrinides, M.C., Mills, N.J., 2009. Demographic effects of pesticides on biological control of Pacific spider mite (Tetranychus pacificus) by the western predatory mite (Galendromus occidentalis). Biol. Control 48, 267-273.

Szczepaniec, A., Creary, S.F., Laskowski, K.L., Nyrop, J.P., Raupp, M.J., 2011. Neonicotinoid Insecticide Imidacloprid Causes Outbreaks of Spider Mites on Elm Trees in Urban Landscapes. PLoS ONE 6, e20018.

doi:10.1371/journal.pone.0020018

Szczepaniec, A., Raupp, M.J., Parker, R.D., Kerns, D., Eubanks, M.D., 2013. Neonicotinoid insecticides alter induced defenses and increase susceptibility to spider mites in distantly related crop plants. PLoS One 8, e62620.

Triplehorn, C.A.J., Borror, N.F., Triplehorn, D.J.C.A., Johnson, N.F., 2005. Borror and DeLong's Introduction to the Study of Insects. 
National Agricultural Statistics Service. 2013. Crop production. Available at www.nass.usda.gov/Publications/Todays_Reports/reports/crop0113.pdf. (accessed on February 12, 2013). USDA-NASS, Washington, DC

Van Steenwyk, R.A., Kiss, A.B. 2010. Mite control in grapes. Arthropod Management Tests 35: C14

Zar, J.H., 1999. Biostatistical analysis 4th edn. N. J. 
Table 1. Effects of insecticide applications on mean (SEM) numbers of individual predator taxa per plant associated with soybean at Volga in 2013 and 2014

\begin{tabular}{llllll}
\hline & Anthocoridae & Syrphidae & Chrysopidae & Coccinellidae & Dolichopodidae \\
\hline $\mathbf{2 0 1 3}$ & & & & & \\
Untreated & $5.00(0.33) \mathbf{a}$ & $0.92(0.62) \mathrm{a}$ & $0.54(0.12) \mathrm{a}$ & $0.3(0.2) \mathbf{a}$ & $1.38(0.07) \mathbf{a}$ \\
Seed & $5.57(0.26) \mathbf{a}$ & $0.85(0.39) \mathrm{a}$ & $0.10(0.12) \mathrm{a}$ & $0.32(0.03) \mathbf{a}$ & $0.96(0.05) \mathbf{b}$ \\
Foliar & $0.73(0.21) \mathbf{b}$ & $1.30(0.38) \mathrm{a}$ & $0.71(0.07) \mathrm{a}$ & $0.06(0.02) \mathbf{b}$ & $0.30(0.05) \mathbf{c}$ \\
Seed+Foliar & $\mathrm{n} / \mathrm{a}$ & $\mathrm{n} / \mathrm{a}$ & $\mathrm{n} / \mathrm{a}$ & $\mathrm{n} / \mathrm{a}$ & $\mathrm{n} / \mathrm{a}$ \\
$\mathbf{2 0 1 4}$ & & & & & $0.42(0.12) \mathrm{a}$ \\
Untreated & $1.28(0.61) \mathrm{a}$ & $0.78(0.31) \mathrm{a}$ & $0.39(0.1) \mathrm{a}$ & $0.13(0.05) \mathrm{a}$ & $0.3(0.11) \mathrm{a}$ \\
Seed & $1.39(0.71) \mathrm{a}$ & $1.20(0.51) \mathrm{a}$ & $0.16(0.05) \mathrm{a}$ & $0.16(0.04) \mathrm{a}$ & $0.37(0.1) \mathrm{a}$ \\
Foliar & $0.36(0.1) \mathrm{a}$ & $0.75(0.34) \mathrm{a}$ & $0.23(0.07) \mathrm{a}$ & $0.09(0.04) \mathrm{a}$ & $0.41(0.13) \mathrm{a}$ \\
\hline Seed+Foliar & $0.09(0.04) \mathrm{a}$ & $1.20(0.57) \mathrm{a}$ & $0.22(0.06) \mathrm{a}$ & $0.06(0.03) \mathrm{a}$ & \\
\hline
\end{tabular}

Means with different letters were statistically different (HSD, Tukey's test; $P<0.05$ ) 
Table 2. Effects of insecticide applications on mean (SEM) numbers of individual predator taxa per plant associated with soybean at South Shore in 2013 and 2014

\begin{tabular}{llllll}
\hline & Anthocoridae & Syrphidae & Chrysopidae & Coccinellidae & Dolichopodidae \\
\hline $\mathbf{2 0 1 3}$ & & & & & \\
Untreated & $0.42(0.1) \mathbf{a}$ & $0.31(0.08) \mathrm{a}$ & $0.53(0.06) \mathrm{a}$ & $0.05(0.01) \mathbf{a}$ & $0.56(0.07) \mathrm{a}$ \\
Seed & $0.30(0.07) \mathbf{a b}$ & $0.37(0.1) \mathrm{a}$ & $0.55(0.06) \mathrm{a}$ & $0.06(0.01) \mathbf{a}$ & $0.55(0.07) \mathrm{a}$ \\
Foliar & $0.12(0.04) \mathbf{b}$ & $0.26(0.06) \mathrm{a}$ & $0.48(0.06) \mathrm{a}$ & $0.02(0.01) \mathbf{b}$ & $0.65(0.08) \mathrm{a}$ \\
Seed+Foliar & $0.12(0.03) \mathbf{b}$ & $0.29(0.06) \mathrm{a}$ & $0.43(0.05) \mathrm{a}$ & $0.02(0.01) \mathbf{b}$ & $0.58(0.06) \mathrm{a}$ \\
2014 & & & & & $0.04(0.15) \mathrm{a}$ \\
Untreated & $0.03(0.02) \mathrm{a}$ & $0.25(0.08) \mathrm{a}$ & $0.17(0.05) \mathbf{a}$ & $0.03(0.01) \mathrm{a}$ & $0.79(0.13) \mathrm{a}$ \\
Seed & $0.04(0.02) \mathrm{a}$ & $0.24(0.06) \mathrm{a}$ & $0.18(0.05) \mathbf{a}$ & $0.01(0.01) \mathrm{a}$ & $0.83(0.14) \mathrm{a}$ \\
Foliar & $0.03(0.02) \mathrm{a}$ & $0.17(0.04) \mathrm{a}$ & $0.05(0.02) \mathbf{b}$ & $0(0) \mathrm{a}$ & $0.78(0.13) \mathrm{a}$
\end{tabular}

\footnotetext{
Means with different letters were statistically different (HSD, Tukey's test; $P<0.05$ )
} 
Table 3. Partial correlations between thrips and major predators

\begin{tabular}{|c|c|c|c|c|c|}
\hline & Anthocoridae & Syrphidae & Chrysopidae & Coccinellidae & Dolichopodidae \\
\hline \multicolumn{6}{|l|}{2013} \\
\hline Volga & $-0.24^{*}$ & -0.12 & $-0.22^{*}$ & -0.18 & $-0.2^{*}$ \\
\hline South Shore & $-0.36^{* * *}$ & $-0.29 * * *$ & $-0.2^{* *}$ & -0.02 & $-0.39 * * *$ \\
\hline \multicolumn{6}{|l|}{2014} \\
\hline Volga & $-0.33^{* *}$ & $-0.3^{*}$ & $-0.36^{* *}$ & -0.09 & $-0.25^{*}$ \\
\hline South Shore & -0.08 & -0.15 & -0.19 & 0 & -0.05 \\
\hline
\end{tabular}

Partial correlation (Pearson's) estimates when controlling for insecticide treatments. Asterisks denote level of statistical significance $(* P \leq 0.05 * * P \leq 0.01 * * * P \leq 0.001)$. 


\section{Figure legends}

Fig. 1. Effect of neonicotinoid and pyrethroid insecticides on soybean aphid. The average density of aphids was compared among treatments at Volga (A) and South Shore (B) in 2013 and 2014. Bars represent means \pm 1 SEM. Means marked with different letters are significantly different from each other within that location and year (Tukey's HSD test; $P<0.05$ ). Numbers of aphids overall were higher at Volga than at South Shore. Foliar applications of insecticides with and without inclusion of seed treatments had a consistent suppressive effect on aphid abundance, while seed treatments varied in their effect on the herbivores.

Fig. 2. Effect of neonicotinoid and pyrethroid insecticides on Thripidae. The average density of thrips was compared among treatments at Volga (A) and South Shore (B) in 2013 and 2014. Bars represent means \pm 1 SEM. Means marked with different letters are significantly different from each other within that location and year (Tukey's HSD test; $P<0.05$ ). Thrips abundance was significantly affected by treatments at Volga in both years, but not at South Shore.

Fig. 3. Effect of neonicotinoid and pyrethroid insecticides on spider mites. The average density of spider mites was compared among treatments in both years at Volga (A) and South Shore (B). Bars represent square root of the means \pm 1 SEM. Abundance of spider mites did not differ significantly among treatments at either location . 
Fig. 4. Effect of neonicotinoid and pyrethroid insecticides on Glycine max yield. Yield was compared among the treatments at Volga in 2013 (A) and 2014 (B) and at South Shore in 2013 (C) and 2014 (D). Bars represent means \pm 1 SE. Means marked with different letters are significantly different from each other (Tukey's HSD test; $P$ $<0.05$ ). Yield of sybean was not affected by insecticide applications with one exception where all insecticide treatments increased average yield of soybean. 
A $\square_{\text {Seed }}^{\text {Untreated }}$

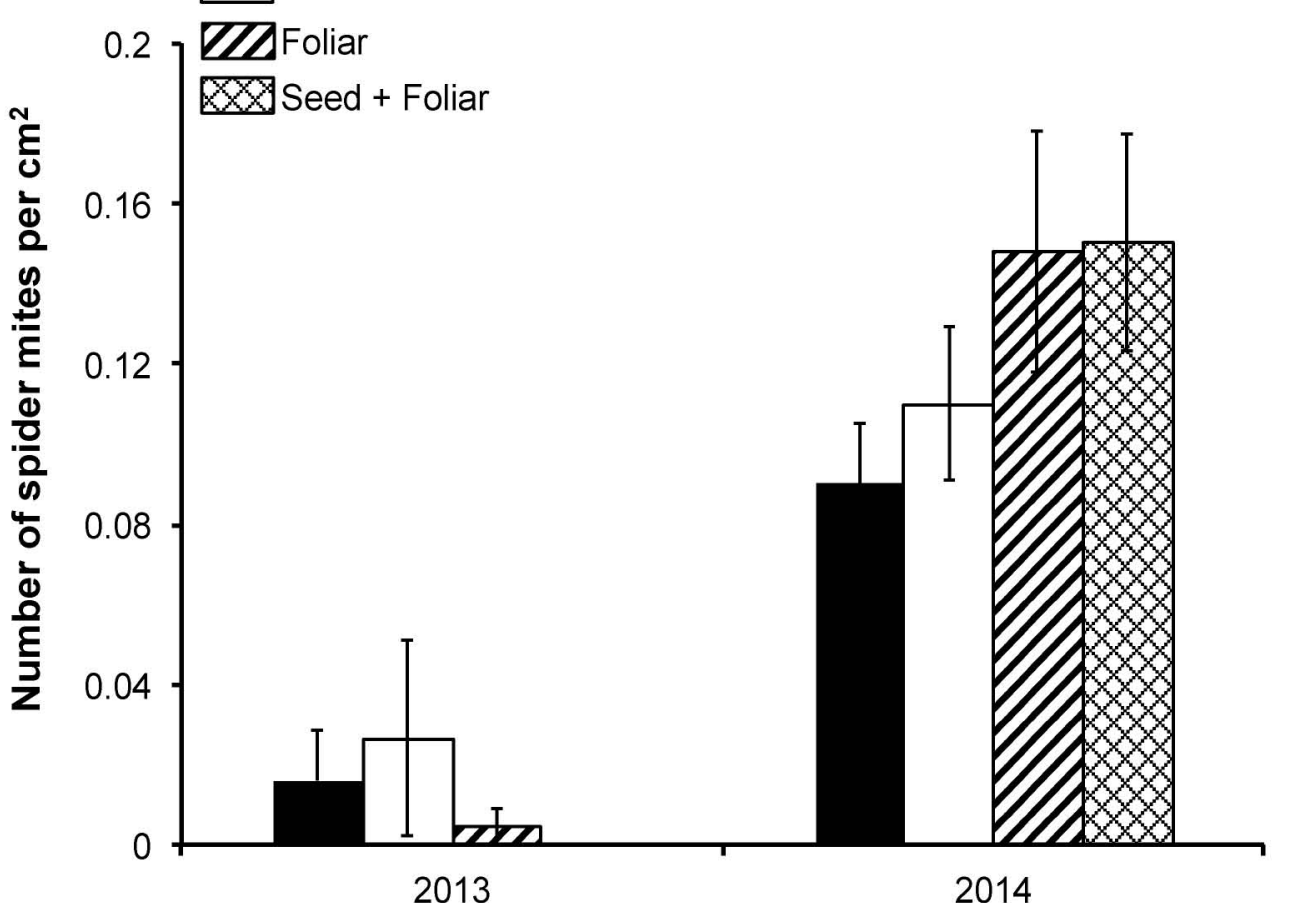

B

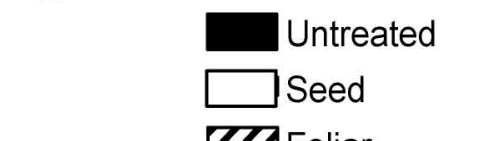

N 0.2 WIA Foliar



South Shore

2013 
A

A Untreated
$\square$ Seed



2013
B
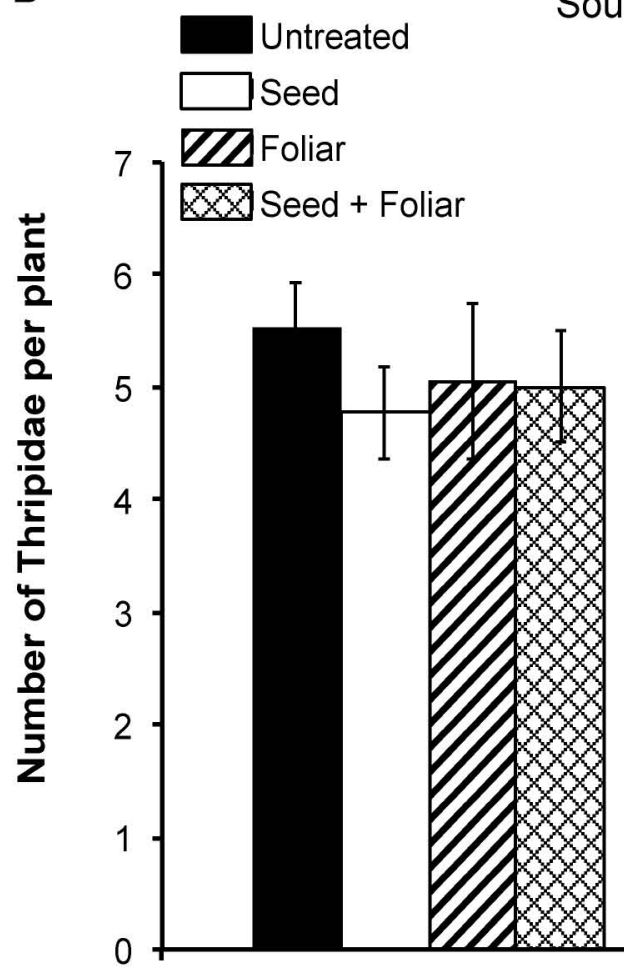

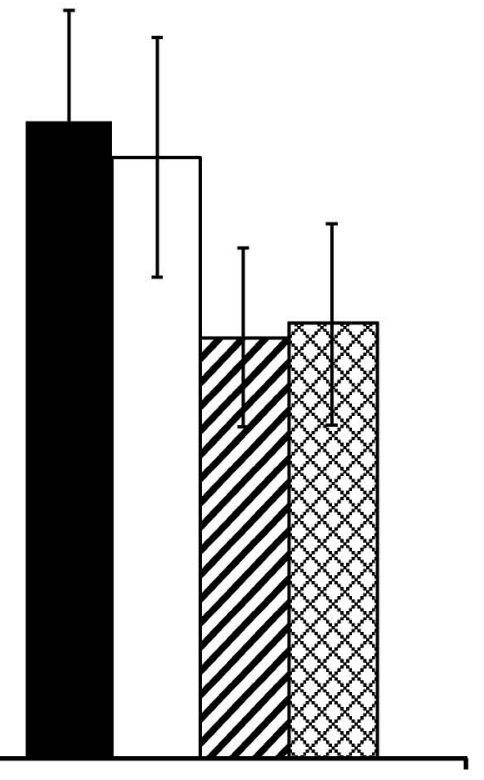

2014 


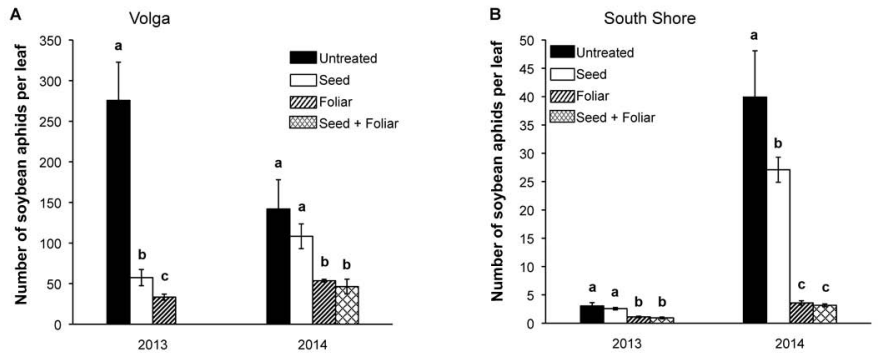

